\title{
ENTRE A DOGMATIZAÇÃO E O ESQUECIMENTO: PAULO FREIRE E A FORMAÇÃO INICIAL DE PROFESSORES
}

\author{
Rosimar Serena Siquelra Esquinsani \\ Universidade de Passo Fundo (UFP), Passo Fundo, Rio Grande do \\ Sul, Brasil
}

\begin{abstract}
Resumo: O texto discute a presença residual da obra de Paulo Freire, na formação docente inicial, a partir de uma pesquisa qualitativa e longitudinal com eixo temporal prospectivo, tendo por base informações coletadas junto a 395 acadêmicos do curso de pedagogia de uma Instituição de Ensino Superior localizada no interior do Rio Grande do Sul, no recorte temporal de 2006 a 2013. O acompanhamento do tema por um período de tempo expandido permitiu estabelecer marcos incidentes, além de localizar recorrências temáticas e comparações. A compilação das informações possibilitou dividir a presença do autor no curso a partir de duas categorias: 0 dogma e o esquecimento; além de sinalizar para o progressivo esvaziamento do pensamento freireano, enquanto base de formação. Como conclusão, aponta-se o possível enfraquecimento do legado freireano na formação daqueles sujeitos.

Palavras-chave: Formação docente inicial. Pedagogia. Paulo Freire. Pesquisa longitudinal.
\end{abstract}

Quando iniciei minha trajetória com formação inicial de professores, Paulo Freire (1921-1997) havia recém-falecido. Vivíamos o impacto de sua morte e, mais do que isso, recebíamos os primeiros legados póstumos de sua obra, alçada à condição singular por/para educadores progressistas e críticos. 
Com o resguardo inicial de quem estuda história da educação e compreende como as dinâmicas históricas se implicam para a consolidação de paradigmas no meio acadêmico, debrucei-me à leitura atenta da obra de Freire, tecendo contrapontos e buscando diálogo com minhas próprias experiências. Presenciei, neste ínterim, o crescimento das ideias freireanas e, como consequência, a tentativa de uso - inadvertido, por parte de alguns - dos aportes de Paulo Freire para explicar todas as situações educacionais vivenciadas no início do século XXI. Ser'freireano' era moda, quase uma profissão de fé. Anacrônicos eram todos os demais que não utilizavam - ao menos em suas retóricas -, frases de efeito do educador pernambucano.

Quando me fixei como docente na Instituição de Ensino Superior onde planejava organizar minha carreira, deparei-me com as mesmas situações que encontrara em outras instituições de ensino por onde havia passado: um Paulo Freire vestido de ícone e discurso, figura certa nos debates apaixonados travados em salas de aula e presença obrigatória nos Projetos Pedagógicos dos cursos de formação de professores.

Nesse momento, já havia me tornado entusiasta da obra de Freire e, justo por essa razão, temia colocar em prova o que, empiricamente, os sentidos me alertavam: nem todo aquele que falava em nome de Freire o utilizava verdadeiramente como epistemologia, como método ou, sequer, relacionava seus escritos com sua (futura) prática pedagógica.

Assim, iniciei, em 2006, uma pesquisa longitudinal (LEE, 2010) com eixo temporal prospectivo (que se inicia no momento da delimitação do problema de pesquisa e acompanha o fenômeno ao longo do tempo), objetivando apreender qual a presença efetiva e residual da obra de Paulo Freire na formação de acadêmicos do curso de Pedagogia.

Para tanto, elaborei uma pesquisa qualitativa baseada na livre resposta a um questionário, aplicado a acadêmicos do curso de pedagogia de uma universidade privada localizada no interior do Rio Grande do Sul. O questionário foi aplicado para 395 acadêmicos que passaram por 20 turmas de graduação, em disciplinas alocadas na segunda metade do curso, desde 2006 a 2013 (ou ao longo oito anos). 
O questionário consistia, basicamente, na interação dialógica a partir de três ordens de perguntas: a) o que Paulo Freire significava para a formação do acadêmico (através da livre indicação de três expressões que caracterizassem a presença do autor em seus estudos); b) quais os conceitos ou excertos teóricos mais utilizados pelo acadêmico e, c) a indicação das principais obras que o acadêmico havia tido contato ao longo do curso.

A cada semestre findo, a cada turma que passava, detinha-me em catalogar as respostas e organizar possíveis indicativos para minha questão inicial, ao menos do ponto de vista contextual da instituição em que desenvolvi a pesquisa: qual a presença efetiva da obra de Paulo Freire na formação de acadêmicos do curso de Pedagogia? Ou ainda: quais as premissas freireanas que aqueles alunos e alunas estavam levando para suas práticas pedagógicas?

Assim, o acompanhamento de um fenômeno, por um período de tempo expandido, permitiu o estabelecimento de marcos incidentes; localizou recorrências temáticas e possibilitou comparações. Além das permanências, através de uma pesquisa longitudinal, também foi possível acompanhar as mudanças do fenômeno, identificando se as mesmas foram obras da ação do tempo ou de interferências externas.

\section{A PRESENÇA de PAUlo Freire NA FORMAÇÃo doCENTE INICIAL: OS ACHADOS DA PESQUISA}

Considerado por muitos como o maior educador brasileiro, Paulo Reglus Neves Freire (Recife, 19 de setembro de 1921 - São Paulo, 02 de maio de 1997) deixou um legado de produção intelectual que transcende gerações e sobrevive a sua ausência física, tanto pela profundidade de suas reflexões, quanto pela pertinência e amplitude das mesmas. Discutir, pois, a presença residual da obra de Paulo Freire na formação inicial de professores coloca-se, como pauta, constantemente em uma condição contemporânea.

No que tange à pesquisa, à compilação das respostas mais efetivas sob o ponto de vista quantitativo (capazes de representar uma recorrência em termos de fenômeno) permitiu dividir as representações mais significativas acerca de Paulo Freire em duas categorias: o dogma e o esquecimento. 
Em relação à primeira categoria, livremente denominada de dogma, a maioria dos alunos entrevistados tinha como horizonte a dogmatização das ideias de Paulo Freire. Tal dogmatização expressava-se, de sobremaneira, quando havia necessidade de sustentar um argumento acadêmico: havia a recorrência ao pensamento de Freire para explicar todo e qualquer fenômeno pedagógico, embasar qualquer discussão, em geral, com o uso de chavões ou clichês de suas obras.

Frases e citações consideradas de efeito ou impactantes, tais como: "[...] ninguém educa ninguém, como tampouco ninguém se educa a si mesmo, os homens se educam em comunhão, mediatizados pelo mundo" (FREIRE, 1987, p. 68); ou “[...] só existe saber na invenção, na reinvenção, na busca inquieta, impaciente, permanente, que os homens fazem do mundo, com o mundo e com os outros. Busca esperançosa também" (FREIRE, 1996, p. 58); ou ainda "ninguém começa a ser educador numa certa terça-feira às quatro a tarde. Ninguém nasce educador ou marcado para ser educador. A gente se faz educador, a gente se forma, como educador, permanentemente, na prática e na reflexão sobre a prática" (FREIRE, 1991, p. 58), eram utilizadas como argumento derradeiro para qualquer discussão, qualquer 'diálogo' em sala de aula, em geral um diálogo muito, muito distante do que propunha o próprio Freire, para o qual:

O diálogo é uma exigência existencial. E, se ele é o encontro em que se solidarizam o refletir e $o$ agir de seus sujeitos endereçados ao mundo a ser transformado e humanizado, não pode reduzir-se a um ato de depositar idéias de um sujeito no outro, nem tampouco tornar-se simples troca de idéias a serem consumidas pelos permutantes. Não é também discussão guerreira, polêmica, entre sujeitos que não aspiram a comprometer-se com a pronúncia do mundo, nem a buscar a verdade, mas a impor a sua (FREIRE, 1996, p. 79, grifo meu).

Em geral, os diálogos travados em sala de aula eram eivados de um pré-conceito arrogante, muito distante das ideias de Freire. O uso frequente de discussões "guerreiras e polêmicas", que serviam mais para distanciar sujeitos do que posicionar suas "pronúncias do mundo", era a tônica.

Tratava-se, pois, de uma retórica "pseudo-freireana" que aparentava ser vazia de conteúdo pois, paradoxalmente, os mesmos alunos que utiliza- 
vam termos como"grande mestre" para definir Paulo Freire, admitiam poucas leituras do referido autor, em geral trechos recomendados ou compilações organizadas por outrem.

Outro achado que legitima tal leitura diz respeito ao purismo dedicado ao pensamento de Freire. Regularmente, os alunos estabeleciam discursos que dividiam suas concepções entre a escola e Paulo Freire, como se a escola e a prática pedagógica fossem incompatíveis com as ideias do educador, afastando suas contribuições do campo histórico de lutas pela educação (algo paradoxalmente incompatível com as contribuições do autor).

Exemplarmente, muitos dos respondentes, quando mencionavam os conceitos mais utilizados por eles, citavam o diálogo ou autonomia na perspectiva freireana, mas faziam adendos como: "pena que na escola é tão difícil", "ainda estamos longe disso em nossa realidade" ou ainda "isso não funciona no chão da escola". Raros os respondentes que indicavam alguma tentativa de estabelecer relações entre a prática cotidiana e os conceitos supostamente apreendidos.

Havia, entretanto, um grupo de respondentes que apresentava uma representação singular para a questão: aqueles que mencionavam que, quando chegassem à escola, "ensinariam" seus colegas - que já estavam lá há mais tempo - a serem freireanos e a praticarem as ideias de Paulo Freire, colocando-se na condição de portadores de uma verdade supostamente consensual e a-histórica.

A pseudo-incompatibilidade entre a teoria e a prática, ou entre o que se diz e o que se faz, parece representar uma contradição ante a efetividade do pensamento do autor, que pontuava:"a teorização deve regressar à prática [...] como uma nova luz. A luz não acrescenta nada ao real, mas permite vê-lo melhor, entendê-lo, captá-lo cientificamente. Enfim, a teoria se faz guia para a ação transformadora do real" (FREIRE; BETTO, 1985, p. 77).

Entretanto, alguns alunos demonstravam ter uma noção exata da historicidade e do campo de tensões e contradições que a realidade da escola representava em seus processos formativos e do quanto essa realidade poderia ascender ao status de campo de operacionalização, sobretudo seguindo os caminhos formativos embasados em Freire, ou sobre "como 
diminuir a distância entre o contexto acadêmico e a realidade de que vêm os alunos, realidade que devo conhecer cada vez melhor, na medida em que estou, de certa forma, comprometido com um processo para mudá-la?" (FREIRE, 1992b, p.177).

Outro dado constatado na pesquisa diz respeito ao que livremente denomino de personificação do mito. Eventualmente, ao longo do recorte temporal examinado, um docente assumia-se discursivamente freireano e, a partir deste momento, condensava e carregava consigo todo o sentido da obra do autor, em detrimento ou sobreposição a todos os demais docentes que, mesmo não declarados freireanos, lançavam mão de práticas coadunadas com as ideias do autor.

Em vários momentos, ao longo do período em relevo, é possível identificar excertos que remetem a um/a professor/a autodeclarado/a freireano/a, que carregaria o estigma de ser o guardião da verdade, representante e, muitas vezes, tradutor peculiar do pensamento do autor.

Tal estigma restava por alçar o/a 'guardião/ã' à condição de único porta-voz do autor, bem como à categoria de saber e de representação deste saber, condição de palpável ambivalência em relação ao pensamento do próprio autor, para o qual ...

Educar e educar-se, na prática da liberdade, não é estender algo desde a "sede do saber", até a "sede da ignorância" para "salvar", com este saber, os que habitam nesta. Ao contrário, educar e educar-se, na prática da liberdade, é tarefa daqueles que sabem que pouco sabem por isto sabem que sabem algo e podem assim chegar a saber mais - em diálogo com aqueles que, quase sempre, pensam que nada sabem, para que estes, transformando seu pensar que nada sabem em saber que pouco sabem, possam igualmente saber mais (FREIRE, 1996, p. 25)

A filiação de um docente ao nome de Paulo Freire também acabava forçando o entendimento de que o mesmo deveria comportar-se como Freire presumidamente se comportaria (!), inclusive aceitando certas flexibilizações epistemológicas que, supostamente, seriam autorizadas em nome do autor. Nessa direção, exemplar foram as colocações de um grupo de alunas reprovadas em uma determinada disciplina:"como a professora foi fazer isso comigo? Ela é freireana!"; ou ainda "uma discípula de Paulo Freire não pode reprovar 
ninguém, isto vai de encontro ao pensamento dele!", bem como outras colocações com teor semelhante e que visavam deslegitimar um processo de avaliação com base no único argumento de que, como a/o docente se dizia freireana/o, hipoteticamente, não poderia adotar ações como reprovar um aluno em sua disciplina.

Esta permissividade vazia não encontra eco nas palavras do autor, ratificando a percepção de que os alunos pouco leram do Freire real, dedicando-se, muitas vezes, ao "achismo" teórico ou ao voluntarismo epistemológico, pois" a professora progressista ensina os conteúdos de sua disciplina com rigor e com rigor cobra a produção dos educandos, mas não esconde sua opção política na neutralidade impossível de seu que-fazer" (FREIRE, 2000, p.44)

Essa primeira categoria resta por estar intimamente ligada à segunda categoria, ou o desconhecimento/esquecimento do pensamento de Freire. Boa parte dos alunos não conhecia a trajetória pessoal e acadêmica de Paulo Freire. Não eram poucos os que ficavam impactados diante da revelação de que Freire não tinha sido pedagogo. As experiências profissionais e a singularidade da vida do educador também eram desconhecidas de boa parte dos alunos. Esse desconhecimento levava os alunos a acreditarem em ideias que seriam supostamente de Freire e que, como tal, deveriam acompanhar a futura prática pedagógica.

Esse desconhecimento/esquecimento também restava por, em alguns casos, impactar na formação do futuro professor de uma maneira contraproducente. Assim, a riqueza dos conceitos e da obra de Freire sucumbia a uma simplificação rasteira, como sinônimo de permissividade e falta de rigor metodológico, que tudo aceita, que qualquer prática - mesmo que eivada de senso comum ou desprovida de uma intencionalidade -, é legitimada por explicações que as vinculam erroneamente a amorosidade (FREIRE, 1987) e boniteza (FREIRE, 1996)

Na mesma direção, caminhava o estudo acadêmico crivado pelo "achismo". Palavras bonitas ou excertos emblemáticos tinham o poder de replicarem-se entre os alunos, não como experiência pedagógica ou como ação metodológica embasada em Freire, mas como um replicar-se identitário que vinculava o autor mais pelo nome do que pelo sentido da obra. 
Tal situação, novamente, colide com as ideias expressas na obra do próprio autor, para quem...

Uma das tarefas mais importantes que deveríamos ter como professores seria não ter a experiência em nome dos alunos. Não podemos fazer isso por eles e elas. Eles e elas têm que ter sua própria experiência, Mas, talvez devêssemos colocar para os alunos e alunas, pelo menos duas vezes por semestre, sobre como estudamos. Como fazemos isso. Eu fazia isso com meus alunos e alunas. Eu tinha o hábito de ler capítulos de livros com os alunos nos cursos de graduação porque muitas vezes, a essa altura, eles ainda não sabiam o que significava ler. Você tem que dar aos alunos e alunas um depoimento sobre o que significa ler um texto. (FREIRE; HORTON, 2003, p. 62-63).

Por fim, uma última constatação diz respeito ao progressivo esvaziamento - aqui denominado de esquecimento - do pensamento de Paulo Freire, identificado na formação dos docentes em especial nos últimos dois anos em destaque. Como se tratou de uma pesquisa longitudinal, notou-se que, nos últimos anos, o nome e o pensamento de Freire, mesmo em chavões, foi minimizado, quase legado à história da educação.

Considerando que o presente texto tem como base as respostas apresentadas pelos discentes diante de um questionário com três perguntas: a) o que Paulo Freire significava para a formação do acadêmico; b) quais os conceitos ou excertos teóricos mais utilizados pelo acadêmico e, c) a indicação das principais obras que o acadêmico havia tido contato ao longo do curso, foi possível materializar o que se denomina de esquecimento pelas recorrências temáticas - ou ausência das mesmas - nas respostas empenhadas.

Exemplarmente, se no início da pesquisa, nos anos de 2006/2007, todos os alunos se diziam identitariamente freireanos, repercutindo a primeira pergunta de maneira consensual, assertiva e direta, com o passar dos anos, este consenso foi arrefecendo. Nos últimos anos da pesquisa - 2012/2013 -, menos de $50 \%$ dos partícipes se diziam freireanos ou atribuíam algum sentido especial à presença de Paulo Freire em sua formação acadêmica.

De igual sorte, as citações de conceitos ou excertos teóricos - ainda que assumindo ares de jargão acadêmico - diminuíram consideravelmente, chegando a pouco mais de $20 \%$ das recorrências nos últimos dois anos da pesquisa. De igual maneira, em relação à terceira questão, cerca de $60 \%$ dos discentes, admitiam pouco ou nenhum contato com a obra do autor. 
Tal situação restou por produzir uma transição confusa entre o dogma e o mito, sem ter, de fato e em alguns casos, passado pela substância de suas ideias no que concerne à formação de professores e o impacto das mesmas no dimensionamento de novos pedagogos.

\section{A PRESEnÇA de PaUlo FreIRE NA FORMAÇÃo dOCENTE INICIAL: AS DISCUSSÕES DA PESQUISA}

Na pesquisa empenhada, foi possível perceber um Paulo Freire tratado como uma teoria inerte na formação daqueles sujeitos. Seja o Paulo Freire alçado à condição de mito e dogma dos primeiros anos, ou o Paulo Freire (injustamente) esquecido, apresentado nos momentos finais da pesquisa, o legado freireano parece não ter se constituído em uma prática viva, em uma efetividade no contexto em estudo.

A presença incipiente e pouco efetiva do legado freireano na formação docente inicial daqueles sujeitos coloca-se como uma situação-problema que merece uma discussão mínima, amparada por duas constatações advindas da empiria.

A primeira constatação vai ao encontro da eventual presença de docentes que "personificavam" o mito Paulo Freire. Tal presença colide com a lógica pedagógica da pergunta, pois não autoriza a existência de dúvidas ante a uma representação personificada do autor. Assim, muitas vezes não se discutia Paulo Freire, mas se ouvia aquilo que outro/a tinha a proclamar em relação ao autor. Tal escuta que, muitas vezes, não era crítica, impedia o surgimento de dúvidas, pois os discentes pareciam acolher interpretações que lhes eram repassadas como um mantra a ser recitado, esquecendo-se que “[...] um dos pontos de partida para a formação de um educador ou de uma educadora, numa perspectiva libertadora, democrática, seria aparentemente essa coisa tão simples: o que é perguntar?" (FREIRE; FAUNDEZ, 2002, p.47).

Tal situação fica muito clara no material empírico examinado, sobretudo nos diversos momentos que discentes manifestavam sua crença inabalável em tudo que supostamente Paulo Freire teria dito/feito/escrito, utilizando para tanto a referência não a uma obra do autor, mas a fala de um docente em sala de aula. 
Uma segunda constatação diz respeito à palidez com que alguns alunos expressavam os conceitos freireanos. Em geral, falava-se sobre autonomia e diálogo sob o ponto de vista do autor, mas tais expressões eram apenas palavras de vocabulário. Dificilmente constituindo-se em uma vivência de sala de aula e prática pedagógica, tanto a autonomia, concebida

[...] enquanto amadurecimento do ser para si, é processo, é vir a ser. Não ocorre em data marcada. É neste sentido que uma pedagogia da autonomia tem de estar centrada em experiências estimuladoras da decisão e da responsabilidade, vale dizer, em experiências respeitosas da liberdade (FREIRE, 1998, p. 121)

Quanto o próprio conceito de diálogo, urdido como uma necessidade existencial e, por força dessa necessidade, também formativa, uma vez que...

E que é o diálogo? Ė uma relação horizontal de A com B. Nasce de uma matriz crítica e gera criticidade (Jaspers). Nutre-se do amor, da humildade, da esperança, da fé, da confiança. Por isso, só com o diálogo se ligam assim, com amor, com esperança, com fé um no outro, se fazem críticos na busca de algo. Instala-se, então, uma relação de simpatia entre ambos. Só aí há comunicação. O diálogo é, portanto, o indispensável caminho (Jaspers), não somente nas questões vitais para a nossa ordenação política, mas em todos os sentidos do nosso ser. Somente pela virtual da crença, contudo, tem o diálogo estímulo e significação: pela crença no homem e nas suas possibilidades, pela crença de que somente chego a ser eles mesmos (FREIRE, 2008, p.115-116).

No contexto examinado - sobretudo nos primeiros anos em relevo - ter autonomia significava filiar-se incondicionalmente à corrente "freireana" (mesmo sem possuir clareza total dos escritos de Freire); enquanto o ato de dialogar muitas vezes significava repetir chavões atribuídos ao autor; propor práticas supostamente defendidas pelo mesmo ou então colocar-se na condição de portador da verdade freireana em um diálogo que "[...] é desamoroso. É acrítico e não gera criticidade, exatamente porque desamoroso. Não é humilde. É desesperançoso. Arrogante. Auto-suficiente" (FREIRE, 2008 , p. 108). Nos anos finais a ideia de autonomia e diálogo arrefeceu. Tais conceitos eram pouco ou quase nunca citados.

A força argumentativa mais candente para tal afirmação vem da presença de termos imperativos utilizados para referendar (?) a obra de Paulo 
Freire: "o professor deve"; "todos devem ler"; "é urgente que..."; "a escola tem que..."; "sabe-se que todos os professores...", entre outras afirmações que confrontam a ideia freireana de diálogo.

Assim, na formação inicial de parte dos professores sujeitos da pesquisa e a partir das repercussões dos mesmos aos questionários, foi possível depreender a existência de um Paulo Freire tratado mais como uma citação do que como epistemologia que possibilita o desenvolvimento de uma consciência protagonista.

Um Paulo Freire incompreendido em sua ideia de formação inicial de professores, pois era apresentado/representado como mito a ser seguido, divergindo da ideia de ação histórica dos sujeitos em formação: "não nasci, porém, marcado para ser um professor assim. Vim me tornando desta forma no corpo das tramas, na reflexão sobre a ação, na observação atenta a outras práticas ou a prática de outros sujeitos, na leitura persistente, crítica, de textos teóricos" (FREIRE, 2001, p. 40).

No momento em que muitos discentes (em especial no início do período em relevo) pareciam eleger Paulo Freire como o autor-mito, afastavam-se diametral e paradoxalmente da opção histórica pelo autor, naquilo que poderíamos chamar de "limpeza" entre a teoria freireana e a prática de Paulo Freire, esquecendo-se de acurar o olhar para torná-lo o"mais crítico possível da realidade, que a 'desvela' para conhecê-la e para conhecer os mitos que enganam e que ajudam a manter a realidade da estrutura dominante" (FREIRE, 1980, p. 29). Naquele contexto, o próprio Freire - investido de mito -, poderia ser traduzido em uma falsa contraposição entre a escola e a academia

Ao dogmatizar as ideias de Freire, muitos dos sujeitos da pesquisa incorriam em um descompasso com as palavras do próprio autor, quando mencionava que "ensinar não é transferir conhecimento, mas criar possibilidades para a sua produção ou a sua construção." (FREIRE, 1996, p.25).

\section{CONSIDERAÇõES FINAIS:}

Se tomarmos as premissas freireanas como dignas de pautar nossas construções teóricas e metodológicas na formação inicial de professores, 
também temos que assim proceder sob o ponto de vista da prática, do contexto histórico.

Na pesquisa encetada, foi possível perceber que a distância entre o discruso embasado nas ideias (e, muitas vezes, só no nome) de Paulo Freire e a prática vivenciada (pautada em outra esfera ou paradigma), restaram por enfraquecer o legado freireano, tornando o autor mais próximo do mito do que da vida cotidiana. A necessidade retórica de afirmar que se lia Freire, não permitiu - em alguns casos -, que se "vivesse" Freire. Com este afastamento discurso/prática o pensamento do autor, infelizmente, foi subjulgado pelo enfraquecimento orgânico.

Na pesquisa em tela, seguramente, os momentos em que os discentes puderam ser "recriadores curiosos" do pensamento de Paulo Freire foram conduzidos pelo exemplo epistemológico da grande maioria dos docentes que, imbuídos de uma referência viva, praticavam as bases da obra de Freire (ou seus princípios) readaptando-os e organizando cada princípio (como diálogo, autonomia, amorosidade...) dentro de uma prática viva, histórica e crítica:

Quanto aos outros, os que põem em prática a minha prática, que se esforcem por recriá-la. E ao fazê-lo, que tenham em mente que nenhuma prática educativa se dá no ar, mas num contexto concreto, histórico, social, cutlrual economico, político, não necessariamente idêntico a outro contexto. Aliás, não tenho nem quero seguidores! Quero recriadores curiosos sobre o que criei, com minha curiosidade epistemológica! (FREIRE, 1982, p. 17)

A pesquisa provoca, derradeiramente, reflexões sobre a necessidade de um "autor-vida" em substituição a um "autor-ícone", evidenciando a recuperação de um sujeito histórico que, com suas experiências e propostas, nos legou um conjunto de escritos que podem contribuir para a construção de propostas epistemológicas coerentes e vivazes, para a formação inicial de professores críticos e protagonistas. 
BETWEEN THE DOGMATIZATION AND THE FORGETTING: PAULO FREIRE AND THE INITIAL FORMATION OF THE TEACHERS

ABSTRACT: The text discusses the residual presence of Paulo Freire's work in the initial teacher training, from a qualitative and longitudinal research with prospective temporal axis, based on information collected beside 395 students of the pedagogy course from an institution of higher education located in the interior of Rio Grande do Sul State, in the time frame 2006-2013. The monitoring of the theme over a period of expanded time, revealed incidents landmarks, in addition to identify thematic recurrences and comparisons. The compilation of the information makes possible to divide the presence of the author in the course from two categories: the dogma and the forgetfulness; as well as indicating the progressive emptying of Freire's thought as basic training. For conclusion, it is pointed out the possible weakening of Freire's legacy in the formation of those subjects.

KEYWORDS: Initial teacher formation. Education. Paulo Freire. Longitudinal research.

\section{ENTRE LA DOGMATIZACIÓN Y EL OLVIDO: PAULO FREIRE Y LA FORMACIÓN DOCENTE INICIAL}

RESUMEN: El texto analiza la presencia residual de la obra de Paulo Freire en la formación inicial del profesorado, a partir de una investigación cualitativa y longitudinal con eje temporal prospectivo, basado en la información recopilada de 395 alumnos del curso de formación en pedagógica de una institución de educación superior localizada en el interior del Rio Grande do Sul, de 2006 a 2013. El seguimiento del estudio durante un periodo de tiempo ampliado, ha permitido establecer marcos incidentes y localizar las recurrencias temáticas y comparaciones. La recopilación de información permitió dividir la presencia del autor en el curso de formación en dos categorías: el dogma y el olvido; también se notó una indicación de abandono progresivo del pensamiento de Freire como base de la formación básica. Concluimos que hay evidencias del posible debilitamiento del legado de Freire en la formación de esos individuos.

Palabras-Clave: Formación inicial del profesorado. Educación. Paulo Freire. La investigación longitudinal.

\section{REFERÊNCIAS}

FREIRE, P. Alfabetização e conscientização. In: . Conscientização: teoria e prática da libertação: uma introdução ao pensamento de Paulo Freire. Tradução Kátia de Melo e Silva. 3. ed. São Paulo: Moraes, 1980. p. 25-56. 
. GUIMARÃES, S. Sobre educação (Diálogos), v. 1. Rio de Janeiro, Paz e Terra, 1982.

; BETTO, F. Essa escola chamada vida: depoimentos ao repórter Ricardo Kotscho. São Paulo, Ática, 1985.

Pedagogia do Oprimido: saberes necessários à prática educativa. 17. ed. São Paulo: Paz e Terra, 1987.

A Educação na Cidade. São Paulo: Cortez, 1991.

; SHOR, I. Medo e ousadia: o cotidiano do professor. 4. ed., Rio de Janeiro: Paz e Terra, 1992.

Professora Sim, Tia Não: Cartas a quem ousa ensinar. 3. ed. São Paulo: Olho d'Água, 1993.

. Pedagogia da Autonomia: Saberes necessários à prática educativa. São Paulo: Paz e Terra, 1996.

A sombra desta mangueira. 3. ed. São Paulo: Olho d'água, 2000.

Política e educação: ensaios. 6. ed. São Paulo: Cortez, 2001. (Coleção Questões da Nossa Época, v. 23).

FAUNDEZ. A. Por uma pedagogia da pergunta. Rio de Janeiro: Paz e Terra, 2002.

HORTON, M. O caminho se faz caminhando: sobre educação e mudança social. 4. ed. Petrópolis: Vozes, 2003.

Educação como prática da liberdade. 31. ed. Rio de Janeiro: Paz e Terra, 2008.

LEE, V. Dados longitudinais em educação: um componente essencial da abordagem de valor agregado no que se refere à avaliação de desempenho escolar. Estudos em Avaliação Educacional, São Paulo, v. 21, n. 47, p. 531-542, set./dez. 2010.

Rosimar Serena Siqueira Esquinsani: Doutora em Educação pela Universidade do Vale do Rio dos Sinos (Unisinos). Atualmente é professora Titular da Universidade de Passo Fundo, atuando no Programa de Pós-Graduação em Educação da Universidade de Passo Fundo. Tem experiência na área de Educação, com ênfase em História da Educação, Administração Educacional e Políticas Educacionais, pesquisando os seguintes temas: políticas educacionais, administração de redes e sistemas de ensino, formação de professores, história da educação e pensamento pedagógico.

E-mail: rosimaresquinsani@upf.br 